\title{
Effect of Propolis on the Fish Muscular Development and Histomorphometrical Characteristics
}

\author{
Salvatore Velotto ${ }^{1}$, Claudia Vitale ${ }^{1}$, Ettore Varricchio ${ }^{2}$, Antonio Crasto $^{1}$ \\ ${ }^{1}$ University of Study of Naples Federico II, Department of Soil, Plant, Environmental and Animal Production \\ Sciences, Faculty of Agriculture, Portici, Italy \\ ${ }^{2}$ University of Study of Sannio, Department of Biological and Environmental Science, \\ Faculty of Science, Benevento, Italy \\ Received September 7, 2009 \\ Accepted June 15, 2010
}

\begin{abstract}
The aim of our study was to evaluate the effect of propolis on mortality of fish eggs due to mycosis, to study its efficacy on the fish growth rate and to analyze the histochemical and ultrastructural characteristics of muscle fibres. We evaluated the muscular development of fish in two different experimental conditions: traditional feeding and feeding with addition of propolis (groups A and B, respectively). The study was carried out on two species of teleosts bred in Italy, Oncorhynchus mykiss (rainbow trout) and Salmo trutta (brown trout). The use of propolis reduced mortality of fish eggs. The muscles were stained for myosin ATPase and succinic dehydrogenase to evaluate fibre type. The area, maximum and minimum diameter for each fibre type in relation to the body length were measured. The animals fed propolis showed a more rapid muscular growth compared to control fed the standard diet. Fibres were larger in the Salmo trutta than in the Oncorhynchus mykiss in both groups. In fish of A group, myotomal muscle, the presence of giant fibres and index of environmental stress was noticed. This type of study is valuable in order to extend the use of propolis as an antifungal agent and a natural product that can improve fish farming.
\end{abstract}

ATPase and SDH activities, specific growth-rate, ultrastructural analysis

European aquaculture has shown a steady increase during the last twenty years, thanks to many initiatives promoted by the European Community to support this sector. But there are still many problems to solve, such as the support of ecocompatible activities, the improvement of animal health and welfare, product quality and consumer health assurance. Propolis is a mixture of various amounts of beeswax and resins collected by the honeybee from plants, particularly from flowers and leaf buds (Krell 1996). The colour of propolis ranges from yellow to dark brown depending on the origin of the resins. Propolis has attracted the researchers' interest in the last decades due to its biological and pharmacological properties, such as immunomodulatory, antitumor, antimicrobial, antiinflammatory, and antioxidant properties (Kanbur et al. 2009). The goal of this study was to analyze, for the first time, the influence of propolis on the fish muscular development and on the structural and ultrastructural characteristics of muscle fibre types. This study opens a new perspective on the investigation of biological properties of propolis, mainly with respect to the influence on the development of the trout and the mortality of fish eggs.

\section{Materials and Methods}

The following species of freshwater fish were used in our study: Salmo trutta (brown trout) and Oncorhynchus mykiss (rainbow trout).

Experiment with eggs

In order to evaluate the effect of propolis on mortality of fish eggs, approximately 600 eggs (half and half) were placed in 3 "Californian tanks" arranged in cascade. Untreated samples (about 250 eggs) were used as control. The eggs were rinsed in propolis solution (1\%) for $15 \mathrm{~min}$, once every four days and then they were counted.

Address for correspondence:

Dr. Phd. Salvatore Velotto

Department of Soil, Plant, Environmental and Animal production Sciences

Faculty of Agriculture, University of Study of Naples "Federico II"

Via Università, 133 - 80055 Portici (NA), Italy

Phone: +390812539269

Fax: +390817762886

E-mail: velotto@unina.it

http://www.vfu.cz/acta-vet/actavet.htm 


\section{Experiment with fish}

Thirty trout of Salmo trutta and thirty trout of Oncorhynchus mykiss were collected from an ichthyogenic intensive establishment. These fish did not derive from growing eggs. Food quantity and quality, and water quality and temperature were monitored. Water temperature was about $15^{\circ} \mathrm{C}$. The fish were acclimatized for one week, and then divided into two groups of 30 fish. The first group (A) was fed the control diet without propolis, the second group (B) was given the basal diet containing propolis. Fish were transferred to water tanks filled with natural spring water and fed for 50 weeks. Each tank contained fish at different developmental stages: alevins and adult fish. The fish were slaughtered during the main phases of the development (the weights and lengths of trout were $100,150,200$ and $250 \mathrm{~g}$ and $15,20,25$ and $30 \mathrm{~cm}$, respectively).

\section{Propolis preparation}

We used hydrodispersible de-waxed propolis extract (from a farm in Campania, southern Italy) that can be used as an active substance, after complete elimination of impurities (pollen, bee hairs, wood fibres). The propolis solution was prepared as follows: $10 \mathrm{~g}$ of propolis were dissolved in $500 \mathrm{ml}$ of water and kept on magnetic agitation, after $4 \mathrm{~h}$, when propolis dissolved into solution, bi-distilled water was added in order to obtain the final volume of one litre and the solution was stored in sealed bottles at $4{ }^{\circ} \mathrm{C}$ until use. The feed included a wetted portion $(50 \%)$ and a dry one made up of grains, seeds and supplements $(50 \%)$ formed into pellets of type OREGON (OP-2). The diet was divided into two parts. One part (group A) without propolis and the second part (group B) was mixed with $1 \%$ propolis extract $\left(10 \mathrm{~g} \cdot \mathrm{kg}^{-1}\right)$. The fish were fed $3 \times$ a day for 50 weeks. The fish to be sampled were anaesthetized with MS 222 (ethyl-m-amino benzoate; $0.4 \mathrm{~g} / \mathrm{l}$ ) and killed.

\section{Growth rate}

After the dietary intake of propolis-containing diets, the specific growth rate (SGR, \% body weight/day) for each group was determined using the equation $\mathrm{SGR}=100\left(\log _{\mathrm{n}} \mathrm{W}_{\mathrm{f}}-\log _{\mathrm{n}} \mathrm{W}_{0}\right) / \mathrm{t}$, where $\mathrm{W}_{0}$ and $\mathrm{W}_{\mathrm{f}}$ were the initial and final weights of each experimental group, respectively, after $t$ days corresponding to experimental conditions (50 weeks).

\section{Histochemistry}

The myotomal muscle was divided in three portions: dorsal, lateral and ventral. From every muscle samples were withdrawn, immediately frozen in liquid nitrogen $\left(-196{ }^{\circ} \mathrm{C}\right)$, and stored at $-80{ }^{\circ} \mathrm{C}$ until histochemistry analyses. The identification of fibre types was performed on $(8 \mu \mathrm{m})$ transverse serial section of the samples using a cryostat (Leica CM 1100) at $-20^{\circ} \mathrm{C}$. The sections were stained histochemically for myosin ATPase (m-ATPase shows the muscular contraction) and succinic dehydrogenase (SDH shows the fibre metabolism) simultaneously on the same muscular fibres (Velotto 2003; Velotto et al. 2005). The method used for the combined histochemical staining (acid m-ATPase + SDH) consisted of different phases. Acid pre-incubation solution was performed at room temperature for $15 \mathrm{~min}$ and was always followed by two 1 -min rinses in $\mathrm{CaCl}_{2}$ in tris hydroxymethyl aminomethane buffer rinse solution. Nitro blue tetrazolium (NBT) incubation was performed for the detection of SDH activity at $37^{\circ} \mathrm{C}$ for $40 \mathrm{~min}$ followed by two rinses in distilled water. For the myofibrillar (acid) ATPase portions, the procedure was performed at $37^{\circ} \mathrm{C}$ at a pH of 9.4 for 50 min together with three 30 -s rinses in $\mathrm{CaCl}_{2}$ solution and incubation for $3 \mathrm{~min}$ in $\mathrm{CoCl}_{2}$ solution. Finally, ammonium sulphide staining of the acid ATPase procedure was performed. Cover slips were placed over the stained tissue sections and fixed in place using glycerol jelly. Additional serial sections were also histochemically stained for detection of basic m-ATPase and $\mathrm{SDH}$ activities.

$\alpha$-amylase-PAS (Periodic acid-schiff reaction)

For the detection of glycogen, the carbohydrate-specific PAS (Periodic acid-schiff reaction) stain was used. In this method, glycol groups were converted to reactive aldehydes by action of the acid; and the Schiff reagent coloured them bright magenta. Polysaccharides are very strongly stained by this method. Periodic acid solution $(0.5 \%)$ was used for incubation for 5 min followed by rinses in distilled water. After that the sections were placed in Schiff reagent for $15 \mathrm{~min}$ and rinsed in water for $5 \mathrm{~min}$. Finally the sections were dehydrated. Cover slips were placed over the stained tissue sections, and fixed in place using glycerol jelly.

\section{Transmission electron microscopy}

Lateral muscle from fish of the size of $15,20,25$ and $30 \mathrm{~cm}$, were fixed in $2.5 \%$ glutaraldehyde in cacodylate buffer $(0.1 \mathrm{M}, \mathrm{pH} 7.4)$ for $3 \mathrm{~h}$ at $4{ }^{\circ} \mathrm{C}$. Samples were subsequently washed in a solution of a $0.35 \%$ saccharose in cacodylate buffer, then postfixed in $1 \% \mathrm{OsO}_{4}$ for $2 \mathrm{~h}$, stained with $4.8 \%$ uranyl acetate in veronal buffer, dehydrated in graded alcohols, washed in propylene oxide and finally embedded in Epon 812 resin. Semithin $(1 \mu \mathrm{m})$ and ultrathin $(50-60 \mathrm{~nm})$ sections were cut with a Reichert Jung (Heidelberger, Germany) ultramicrotome. Semithin sections were stained with aqueous saturated uranyl acetate and Reynolds lead citrate, and viewed in Zeiss EM 109 at $80 \mathrm{kv}$ (E1-Matbouli et al. 2002).

\section{Fibre size}

Fibre size was determined from the same section used to determine myofibre number. For each fibre type using an image-analysing system LAS (Leica Application Suite Interactive measurement) the area, maximum and minimum diameter were measured. For each muscle, at least 200 fibres, belonging to eight random fields, were considered. 
Statistical analysis

A general linear model (GLM) in the statistics package SPSS (SPSS Inc., Chicago, IL, USA) was used to test for changes in muscle fibres with propolis added to the feed. A group of fish with traditional feed was included in the model to quantify inter-individual variability. A GLM was also used in order to test the same variables.

\section{Results}

The analysis of eggs treated with propolis showed a gradual reduction in mortality. Moreover, during the first days a reduction in mortality of $1.2 \%$ was observed (compared to untreated eggs) and in the last days mortality was reduced by $2 \%$ (compared to eggs untreated).

\section{Fibre types}

The histochemical analysis showed that the lateral musculature of the two studied teleosts was made up of three differentiated muscular layers: red (superficial), pink (intermediate), and white (deep). The superficial muscular layer consisted of red fibres (R1 and R2: large and small fibres, respectively) in both species and in each growth stage (Plate II, Figs $1,2)$. Such fibre types were acid-stable and alkali-labile, and they were located along the lateral line like a heavily stained triangle in cross-section. The red fibres had aerobic metabolism and slowly hydrolyzed ATP. The intermediate muscular layer consisted of pink fibres (P1 and P2: large and small fibres, respectively) in both species and in each growth stage. Such fibre types were acid-labile and alkali-stable, they showed repetitive activity at sustained speed. Our research showed that in both the studied species and, independently from the feeding, the transition between pink and white muscle was gradual: pink fibres progressively became larger and lost their characteristic m-ATPase activity, acquiring that of the white fibres (Plate III, Fig. 3).

The deep muscular layer was differently organized, according to the size of the species tested. In trout of the body length of $15-20 \mathrm{~cm}$, the fibres of the main muscular mass were all negative for the acid m-ATPase reaction. Such fibres were all white (W1 and W2: large and small fibres, respectively) and were acid-labile and alkali-stable, they were involved in fast movements and restored their energetic reserves during the rest phases. There were few mitochondria, probably because the energetic demand was high in the time and the mitochondrial system was not able to satisfy it. The same trend was found in trout of the body length of $20-25 \mathrm{~cm}$ in both species fed traditionally and with propolis. Animals of larger size (25-30 $\mathrm{cm}$ in length) of both tested groups showed differences between the two species. In the brown trout, it was possible to classify the white portion of the myotome as a mosaic made up of red and white fibres of variable size (Plate III, Fig. 4). They were: red 1 (R1) of small diameter and high oxidative enzyme activity, small white and large white (W2 and W1) of medium and large diameter with high glycolytic enzyme activity. Moreover, our study showed that in brown trout, the red 1 fibres belonging to the mosaic zone differed for the succinic dehydrogenase and m-ATPase activities with respect to the superficial red 1 fibres. In the rainbow trout, the biochemical activity of the fibres was similar, therefore, it was impossible to differentiate morphologically red and white fibres in the mosaic muscle. Our results show that the edible part of the trout musculature is mostly composed of white muscular fibres.

\section{Body length and fibre type}

The results showed an increase of fibre area in fish with the length of $15-20 \mathrm{~cm}$. It was possible notice a decrease of fibre area in fish with the length of $20-25 \mathrm{~cm}$, finally there was a new increase in fish with the length of $25-30 \mathrm{~cm}$. The differences between the species belonging to groups $\mathrm{A}$ and $\mathrm{B}$ are indicated in Table 1.

\section{Fibre size}

The mean area of fibre types considered in Salmo trutta was larger than in 
Table 1. Mean value and variation coefficient (v.c.,\%) of morphometric characteristics analyzed in relation to fish length.

\begin{tabular}{|c|c|c|c|c|c|c|c|c|}
\hline \multirow{3}{*}{ Species } & \multicolumn{6}{|c|}{ Fish length $(\mathrm{cm})$} & \multirow{2}{*}{\multicolumn{2}{|c|}{30}} \\
\hline & \multicolumn{2}{|c|}{15} & \multicolumn{2}{|c|}{20} & \multicolumn{2}{|c|}{25} & & \\
\hline & mean & v.c. $\%$ & mean & v.c., $\%$ & v.c., $\%$ & v.c., & mean & v.c. $\%$ \\
\hline \multicolumn{9}{|l|}{ Group A } \\
\hline \multicolumn{9}{|c|}{ Area, $\mu^{2}$} \\
\hline Salmo trutta & 3066.03 & 7 & 3676.05 & 5 & 3405.11 & 6 & 3725.15 & 5 \\
\hline Oncorhynchus mykiss & 2116.17 & 9 & 2584.25 & 4 & 2325.08 & 9 & 2560.18 & 4 \\
\hline \multicolumn{9}{|c|}{ Minimum diameter, $\mu$} \\
\hline Salmo trutta & 29.12 & 27 & 32.32 & 25 & 30.22 & 20 & 34.33 & 23 \\
\hline Oncorhynchus mykiss & 30.52 & 19 & 34.13 & 17 & 31 & 19 & 36.42 & 19 \\
\hline \multicolumn{9}{|c|}{ Maximum diameter, $\mu$} \\
\hline Salmo trutta & 63.29 & 20 & 69.55 & 16 & 65.37 & 24 & 74.18 & 19 \\
\hline Oncorhynchus mykiss & 60.22 & 18 & 66.23 & 15 & 63.16 & 19 & 70.51 & 14 \\
\hline \multicolumn{9}{|l|}{ Group B } \\
\hline \multicolumn{9}{|c|}{ Area. $\mu^{2}$} \\
\hline Salmo trutta & 2486.08 & 8 & 3076.07 & 5 & 2805.01 & 5 & 3134.2 & 7 \\
\hline Oncorhynchus mykiss & 1716.1 & 6 & 2284.25 & 4 & 1825 & 8 & 3161.28 & 3 \\
\hline \multicolumn{9}{|c|}{ Minimum diameter, $\mu$} \\
\hline Salmo trutta & 39.1 & 7 & 46.33 & 13 & 41.23 & 7 & 49.33 & 10 \\
\hline Oncorhynchus mykiss & 28.5 & 10 & 34.08 & 9 & 30 & 10 & 42.43 & 16 \\
\hline \multicolumn{9}{|c|}{ Maximum diameter, $\mu$} \\
\hline Salmo trutta & 62.33 & 14 & 73.46 & 11 & 68.07 & 17 & 82.1 & 13 \\
\hline Oncorhynchus mykiss & 52 & 11 & 56.2 & 18 & 53 & 17 & 65 & 7 \\
\hline
\end{tabular}

Table 2. Comparison between mean value of the morphometric characteristics of fibre type and type of feeding.

\begin{tabular}{|l|c|c|c|c|c|c|}
\hline \multirow{2}{*}{ Species } & \multicolumn{7}{|c|}{ Fibre types ${ }^{(*)}$} \\
\cline { 2 - 7 } & ${\mathrm{W} 1 \mathrm{~d}^{\mathrm{a}}-\mathrm{W} 1 \mathrm{~d}^{\mathrm{b}}}_{7}$ & $\mathrm{~W} 2 \mathrm{~d}^{\mathrm{a}}-\mathrm{W} 2 \mathrm{~d}^{\mathrm{b}}$ & $\mathrm{W} 1 \mathrm{v}^{\mathrm{a}}-\mathrm{W} 1 \mathrm{v}^{\mathrm{b}}$ & $\mathrm{W} 2 \mathrm{v}^{\mathrm{a}}-\mathrm{W} 2 \mathrm{v}^{\mathrm{b}}$ & $\mathrm{P}^{\mathrm{a}}-\mathrm{P} 1^{\mathrm{b}}$ & $\mathrm{R}^{\mathrm{a}}-\mathrm{R} 1^{\mathrm{b}}$ \\
\hline Salmo trutta & $600.08^{* * *}$ & $303^{* * *}$ & $625.93^{* * *}$ & $400.03^{* * *}$ & $426^{* * *}$ & $202.89^{* * *}$ \\
\hline Oncorhynchus mykiss & $600.02^{* * *}$ & $241.07^{* * *}$ & $605.92^{* * *}$ & $200.30^{* * *}$ & $480.63^{* * *}$ & $296.11^{* * *}$ \\
\hline \multicolumn{7}{|c|}{ Minimum diameter, $\mu$} \\
\hline Salmo trutta & $18.9 * * *$ & $15.01^{* * *}$ & $5.11^{*}$ & $14.01^{* * *}$ & $11^{* *}$ & 2.2 \\
\hline Oncorhynchus mykiss & 4 & 0.85 & $15.97^{* * *}$ & 2099 & $7.9^{* *}$ & 1.1 \\
\hline \multicolumn{7}{|c|}{ Maximum diameter, $\mu$} \\
\hline Salmo trutta & $20.05^{* * *}$ & $11.87^{* *}$ & $11.09^{* *}$ & $9.1^{*}$ & $17.24^{* * *}$ & $7.01^{*}$ \\
\hline Oncorhynchus mykiss & $19.89^{* * *}$ & 5.47 & 6.35 & $12^{* *}$ & $12.91^{* *}$ & $6.97^{*}$ \\
\hline
\end{tabular}

${ }^{(*)}$ W1d: large white fibres of the dorsal region; W2d: small fibres of the dorsal region; W1v: large white fibres of the ventral region; W2v: small fibres of the ventral region; P1: pink fibres of the central region; R1: red fibres of the superficial region. $* * * P<0.001 ; * * P<0.01$;

a) Animals fed traditional feed; b) Animals fed propolis

Oncorhynchus mykiss both in group A and in group B. The results highlighted that the fibres were larger in Salmo trutta than in Oncorhynchus mykiss, both in group A and in group B. Particularly significant differences between dorsal, ventral, intermediary and superficial red fibres were noticed in both groups $(P<0.001$, Table 2$)$. We studied the morphometric characteristics of these species in order to characterize these fish. In particular, we noticed that fish of group B showed smaller fibres than fish of group A (Table 3). 
Table 3. Comparison between mean value of the morphometric characteristics and type of feeding.

\begin{tabular}{|l|c|c|c|c|}
\hline Species & \multicolumn{4}{|c|}{ Comparison } \\
\hline & $15^{\mathrm{a}}-15^{\mathrm{b}}$ & $20^{\mathrm{a}}-20^{\mathrm{b}}$ & $25^{\mathrm{a}}-25^{\mathrm{b}}$ & $30^{\mathrm{a}}-30^{\mathrm{b}}$ \\
\hline \multicolumn{5}{|c|}{ Area, $\mu^{2}$} \\
\hline Salmo trutta & $579.05^{* * *}$ & $499.98^{* * *}$ & $500.1^{* * *}$ & $499.95^{* * *}$ \\
\hline Oncorhynchus mykiss & $600.07^{* * *}$ & $500^{* * *}$ & $500^{* * *}$ & $498.9^{* * *}$ \\
\hline \multicolumn{5}{|c|}{ Minimum diameter, $\mu$} \\
\hline Salmo trutta & $10.02^{* * *}$ & $7.99^{* *}$ & $10.99^{* * *}$ & $15^{* * *}$ \\
\hline Oncorhynchus mykiss & $12.02^{* * *}$ & $10.05^{* * *}$ & $11^{* * *}$ & $10.99^{* * *}$ \\
\hline \multicolumn{5}{|c|}{ Maximum diameter, $\mu$} \\
\hline Salmo trutta & $18^{* * *}$ & $16.09^{* * *}$ & $16.96^{* * *}$ & $16.95^{* * *}$ \\
\hline Oncorhynchus mykiss & $18.22^{* * *}$ & $20.03^{* * *}$ & $20.16^{* * *}$ & $15.51^{* * *}$ \\
\hline
\end{tabular}

$* * * P<0.001 ; * * P<0.01$

a) Animals fed traditional feed; b) Animals fed propolis

\section{Effect of propolis on growth}

Fish fed propolis for up to 50 weeks were little affected. The specific growth rate, for example, was not significantly affected by the dietary intake of propolis. The SRG value for the control fish was 0.27 , and 0.19 in the groups receiving 0 and $10 \mathrm{~g}$ propolis $\cdot \mathrm{kg}^{-1}$ diet, respectively.

The comparison analysis among the two groups (A and B) highlighted the advantages of using propolis. Growth speed was increased in trout of group B compared to trout of group A. Trout of group B (fed propolis) reached about $30 \mathrm{~cm}$ in length within 47 weeks (weighing about $300 \mathrm{~g}$ ). Trout belonging to group A (fed in the traditional way) reached about $30 \mathrm{~cm}$ in length within 50 weeks (weighing about $300 \mathrm{~g}$ ). The development of A compared to B was greater in the first period of growth (up to $15 \mathrm{~cm}$ ). The later stages of growth were similar for trout of both groups (between 15 and $30 \mathrm{~cm}$ ). The PAS method indicated the presence of giant fibres in the control group and in the fishes of greater size.

\section{Ultrastructure}

The ultrastructural analysis was performed using the Transmission Electron Microscopy (TEM) technique and showed a different quantitative distribution of the mitochondria in the different fibre types. In the $\mathrm{W}$ fibres, the number of mitochondria was low, in the $\mathrm{R}$ fibres an elevated number of mitochondria were found, finally in the P fibres few peripherally localized mitochondria were noticed (Plate IV, Fig 5).

\section{Discussion}

The trout eggs, like those of other salmonid fish species, are particularly threatened by mycotic infections, mainly for two reasons. First, this is the result of salmonid reproduction biology itself; second, it is due to the ecodevelopment of aquatic zoosporic fungi (Czeczuga et al. 2005). Silici et al. (2007) assessed that in spite of the great differences in the chemical composition of propolis from different geographic location, all samples exhibited significant antifungal activity. We noted a reduction $(P<0.001)$ in mortality in the treated eggs with propolis. This effect confirms the biological properties of propolis as an antimicrobial, antifungal, antiprotozoan and antiviral agent (Krell 1996).

\section{Ultrastructure}

In order to study the effect of propolis on fibre development, we carried out an ultrastructural analysis of two groups of fish. Fish myotomal muscle types are structurally, metabolically and functionally distinct (Bartol 2001). The ultrastructural analysis showed 
high density of mitochondria in the red muscle and low content of mitochondria in the white muscle. Pink muscle was intermediate in structure, metabolism, and contractile properties between red and white muscle (Coughlin et al. 1996). Our results, however, showed that the ultrastructure was not affected by the dietary intake of propolis.

\section{Fibre type}

Fish muscle differs from the skeletal muscle of other vertebrates by the continued recruitment of new fibres during a large part of the vital cycle. Therefore the presence of fibres with different dimensions may indicate a different mechanism of histogenesis of new fibres in the deep muscle layer in the early and adult stages (Scapolo et al. 1988). In agreement with Mosse (1979), we noticed that the ATPase activity of fish muscle fibres was more sensitive to $\mathrm{pH}$ treatment than those of other vertebrates. White fibres, however, showed positive reactions for ATPase but only after short periods of alkaline preincubation (Te Kronnie et al. 1983). The most stable were intermediate fibres, which displayed stability after alkaline as well as acid pre-treatment. The superficial layer of the two studied teleosts consists of fibres that form the red muscle, they are intensely stained for the presence of aerobic enzymes.

The fibres of the myotomal intermediate area have similar enzymatic characteristics in the analyzed fish and show intermediate oxidative activity and moderate m-ATPase activity. Similar characteristics have been described in the guppy, rock goby, goldfish, mullet and catfish (Mascarello et al. 1986).

In agreement with Lopez-Albors (1998), this study highlights that the pink muscle actively contributes to the hyperplastic growth of the red and white muscle.

\section{Body length and fibre type}

Our results show that the brown trout in the myotomal deep layer (from $20 \mathrm{~cm}$ onwards) shows the presence of three fibres types: large white and small white (W1 and W2) and R1. Such structure allows confirmation that the brown trout live in calm and sheltered waters. Our results suggest that the differentiation that occurs during development can be due to a continuous recruitment of new fibres by the most superficial layer, according to Ibabe Martinez et al. (2000) (Plate IV, Fig. 5). In the rainbow trout, instead, the deep musculature consists of large white and small white fibres (W1 and W2) fast contracting and glycolytic, able to perform high efforts in short time. Such fibre types could explain the presence of the rainbow trout in more dynamic environments. This species can be considered suitable for aquaculture development and then to repopulate rivers and lake.

The analysis of the morphometric data shows different dimensions of the lateral musculature of the two studied species fed in the traditional way and with propolis. The fibre cross sectional area is a good indicator of body size in teleosts. The feeding with propolis allowed a faster development in fish of group B compared to fish of group A (47 weeks vs. 50 weeks). The deep musculature of the brown trout consists of both large diameter and small diameter white fibres. The same trend was found in both groups (A and B). However, fish of group B show fibres of smaller size compared to fish of group A. These results confirm the hypopthesis that the type of farming and feeding affect body growth. Comparing the morphometric indicators of different fibres, Salmo trutta has greater mean values than the Oncorhynchus mykiss. Previous studies have underlined the inverse correlation between the diameter and area of the muscular fibres and compactness of fish meat. It can therefore be affirmed that the rainbow trout have a higher degree of juiciness, elasticity and compactness than the brown trout (Hurling et al. 1996; Johnston 2000). We noticed in both species and groups a reduction of the morphometric values between 20 and $25 \mathrm{~cm}$ in length. A large variation in fibre size was observed in all classes of fish, being more pronounced in white musculature (Dal Pai et al. 2000). In the red and pink musculatures of sexually mature specimens a large amount of new $(<20 \mu \mathrm{m})$ fibres was confirmed (Dal Pai et al. 2000). This hyperplastic growth was accompanied 
by a continuous increase in fibre diameter (hypertrophy) and the occurrence of new fibres represents a continuation of myogenesis during juvenile and young-adult life. The absence of such small fibres in the caudal region of adult rainbow trout $(>39 \pm 40 \mathrm{~cm})$ was associated with the end of hyperplastic growth (Weatherley et al. 1980; Stickland 1983). Similar observations were made in a wide range of seawater species (Kundu and Mansuri 1992). However, juvenile and young-adult muscle growth is largely dependent on the amount of small and new fibres formed during the larval period and also in the early juvenile stages (Talesara and Urf 1985). Besides, we noticed that there were giant fibres, especially in the brown trout of group A. These fibres were found in other fish and mammalians (Acosta et al. 2005; Schubert-Schoppmeyer et al. 2008) and they were correlated with poor meat quality. Finally, as previously described, the SGR was not significantly affected by the dietary intake of propolis at $10 \mathrm{~g}$ propolis $\cdot \mathrm{kg}^{-1}$ diet according to the results of Cuesta et al. (2005) and in discordance with Abd-El-Rhman (2009) according to who propolisethanolic - extract and crude propolis evoked the highest specific growth rate.

Several authors have demonstrated the biological benefits of propolis but it is hard to compare the present findings and the current results with the literature because reports on the addition of propolis to diets deal with its effects on the immune response in fish (Cuesta 2005; Chu 2006). Talas (2009) reported that propolis has protective haematological and biochemical effects on rainbow trout. Meurer (2009) indicated the potential use of brown propolis extract as a growth promoter to Nile tilapia fingerlings. Our study finds that the addition of propolis to the diet of trouts leads to the improvement of life characteristics of the aquaculture fish. It influences positively the growth of the muscle and the quality of meat of the two considered species. In fact, there is a positive correlation between the use of propolis, development of fish and survival of eggs. However, there is still a need for further studies regarding the use of the propolis extract and its chemical constituent, for environmental distribution as possible food supplements and natural protective agent.

\section{References}

Acosta J, Carpio Y, Borroto I, Gonzalez O, Estrada MP 2005: Myostatin gene silenced by RNAi show a zebrafish giant phenotype. J Biotech 119: 324-331

Bartol IK 2001: Role of aerobic and anaerobic circular mantle muscle fibers in swimming squid: Electromyography. Biol Bull 200: 59-66

Chu WH 2006: Adjuvant effect of propolis on immunization by inactivated Aeromonas hydrophila in carp (Carassius auratus gibelio). Fish Shellfish Immunol 21: 113-117

Coughlin DJ, Zhang G, Rome LC 1996: Contraction dynamics and power production of pink muscle of the scup (Stenotomus chrysops). J Exp Biol 199: 2703-2712

Cuesta A, Rodriguez A, Esteban MA, Meseguer J 2005: In vivo effects of propolis, a honeybee product, on gilthead seabream innate immune responses. Fish Shellfish Immunol 18: 71-80

Czeczuga B, Bartel R, Kiziewicz B, Godlewska A, Muszyńska E 2005: Zoosporic fungi growing on the eggs of sea trout (Salmo trutta m. trutta L.) in river water of varied trophicity. Pol J Environ Stud 14: 295-303

Dal Pai V, Dal Pai-Silva M, Carvalho ED, Fujiara CY, Gregorio EA, Curi PR 2000: Morphological, histochemical and morphometric study of the myotomal muscle tissue of the pacu (Piaractus mesopotamicus Holmerg 1887: Sarrasalminae, characidae, Teleostei). Anat Histol Embryol 29: 283-289

El-Matbouli M, Hoffmann RW 2002: Influence of water quality on the outbreak of proliferative kidney disease field studies and exposure experiments. J Fish Dis 25: 459-467

Hurling R, Rodell JB, Hunt HD 1996: Fibre diameter and fish texture. J Texture Stud 27: 679-685

Ibabe Martinez I, Gil Cano F, Ramirez Zarzosa G, Vazques JM, Latorre R, Lopez Albors O, Arencibia A, Orenes M 2000: Histochemical and morphometric aspect of the lateral musculature of different species of teleost marine fish of the percomorphi order. Anat Histol Embryol 29: 211-219

Johnston IA, Anderson R, Sandham C, Dingwall A, Mitchell D, Selkirk C, Nickell D, Baker R, Robertson B, Whyte D, Springate J 2000: Muscle fibre density in relation to the colour and texture of smoked Atlantic salmon (Salmo salar L.). Aquaculture 189: 335-349

Kanbur M, Eraslan G, Silici S 2009: Antioxidant effect of propolis against exposure to propetamphos in rats. Ecotox Environ Saf 72: 909-915

Krell R 1996: Value-added products from beekeeping: Chapter 5: propolis. FAO Agriculture Services Bulletin; 124 
Kundu R, Mansuri A 1992: Growth of pectoral muscle fibres in relation to somatic growth in some marine fishes. Neth J Zool 42: 595-606

Lopez-Albors O, Gil F, Ramirez-Zarzosa G, Vazques JM, Latorre R, Garcia-Alcazar A, Arencibia A, Moreno F 1998: Muscle development in gilthead sea bream (Sparus aurata, L.) and sea bass (Dicentrarchus Zabrax, L.): Further histochemical and ultrastructural aspects. Anat Histol Embryol 27: 223-229

Mascarello F, Romanello MG, Scapolo PA 1986: Histochemical and immunohistochemical profile of pink muscle fibres in some teleosts. Histochem Cell Biol 84: 251-255

Meurer F, da Costa MM, de Barros DAD, Teixeira S, de Oliveira L, da Paixao PS 2009: Brown propolis extract in feed as a growth promoter of Nile tilapia (Oreochromis niloticus, Linnaeus 1758) fingerlings. Aquaculture Res 40: 603-608

Mosse PRL 1979: Capillary distribution and metabolic histochemistry of the lateral propulsive musculature of pelagic teleost fish. Cell Tissue Res 203: 141-160

Scapolo PA, Veggetti A, Mascarello F, Romanello MG 1988: Developmental transitions of myosin isoforms and organization of the lateral muscle in the teleost Dicentrarchus labrax (L.). J Anat Embr 178: 287-295

Schubert-Schoppmeyer A, Fiedler I, Nurnberg G, Jonas L, Maak S, Rehfeldt C 2008: Simulation of giant fibre development in biopsy samples from pig longissimus muscle. Meat Sci 80: 1297-1303

Silici S, Unlu M, Vrdar Unlu G 2007. Antibacterial activity and phytochemical evidence for the plant origin of Turkish propolis from different regions. World J Microbial Biotechnol 23: 1797-1803

Stickland NC 1983: Growth and development of muscle fibres in the rainbow trout (Salmo gairdneri). J Anat 137: $323-333$

Talas ZS, Gulhan MF 2009: Effects of various propolis concentrations on biochemical and hematological parameters of rainbow trout (Oncorhynchus mykiss). Ecotox Environ Saf 72: 1994-1998

Talesara CL, Urfi AJ 1985: A histophysiological study of muscle differentiation and growth in the common carp, Cyprinus carpio, var communis. J Fish Biol 31: 45-54

Te Kronnie G, Tatarczuch L, Van Raamsdonk W, Kilarski W 1983: Muscle fiber types in the myotome of sticklebach, Gasterostus aculeatus L.; a histochemical, immunohistochemical and ultrastructural study. J Fish Biol 22: 303-316

Velotto S 2003: Caratterizzazione del miotomo e dell'apparato digerente in teleostei. Studio su Salmo (Trutta) Trutta e Oncorhynchus Mykiss. (Characterization of myotome and digestive system in fishes. Study on Salmo (trutta) trutta and Oncorhynchus mykiss.) PhD. Thesis, Univ Fed II Agric, Italy, $242 \mathrm{p}$

Velotto S, Perrucci G, Stasi T, Di Prisco MR, Ratto A, Crasto A 2005: Study of the muscular development in 2 teleosteis: application of eco-compatibles breeding techniques. Biol Mar Medit 12: 237-239

Weatherley A, Gill H, Rogers S 1980: Growth dynamics of mosaic muscle fibres in fingerling rainbow trout (Salmo gairdneri). Can J Zool 58: 1535-1441 
Plate II

Velotto S. et al.: Effect of Propolis ... pp. 543-550

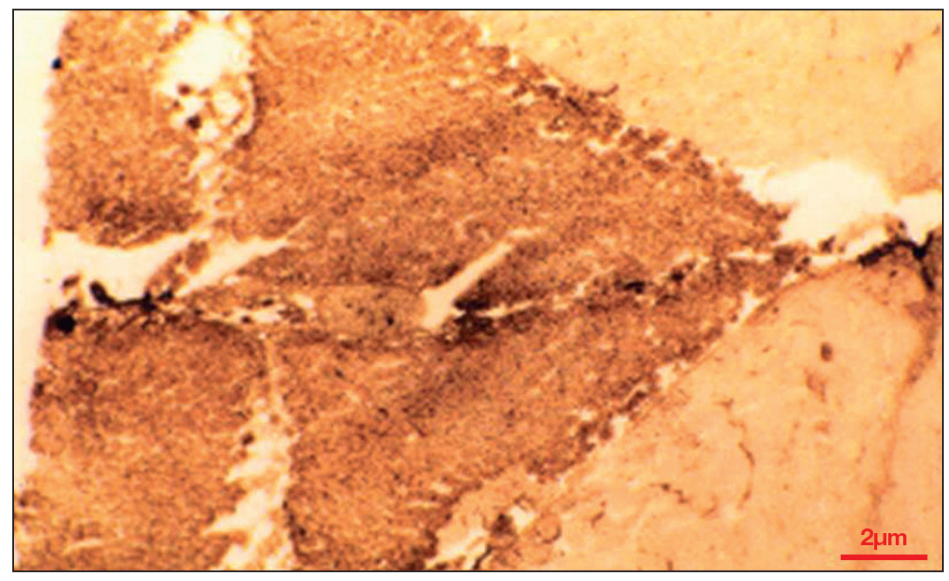

Fig. 1. Oncorhynchus mykiss. The cross-section of the intermediate muscle layer by acid m-ATPase reaction. Three differentiated muscular layers: red (superficial), pink (intermediate), and white (deep).

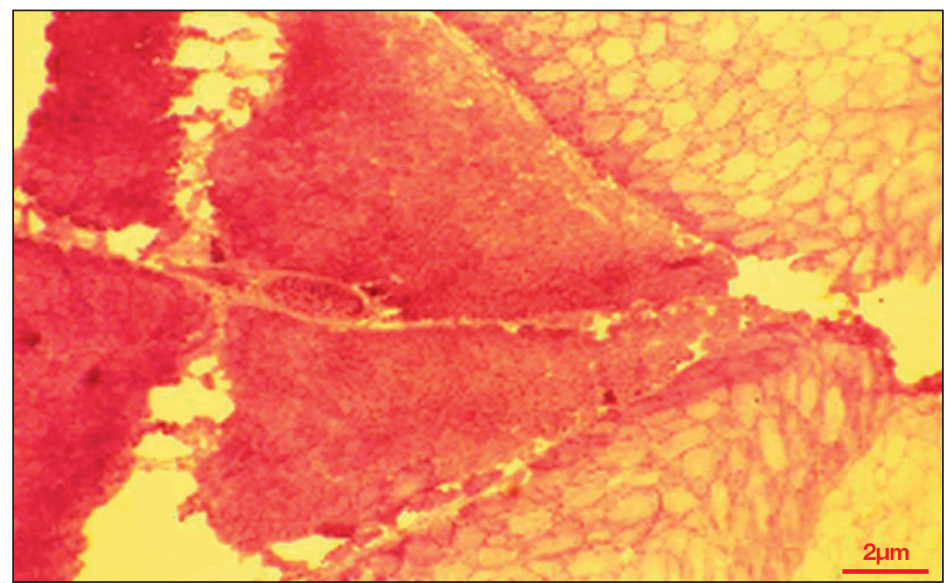

Fig. 2. Oncorhynchus mykiss. The cross-section of the intermediate muscle layer by PAS (Periodic Acid Schiff). Three differentiated muscular layers: red (superficial), pink (intermediate), and white (deep). 
Plate III

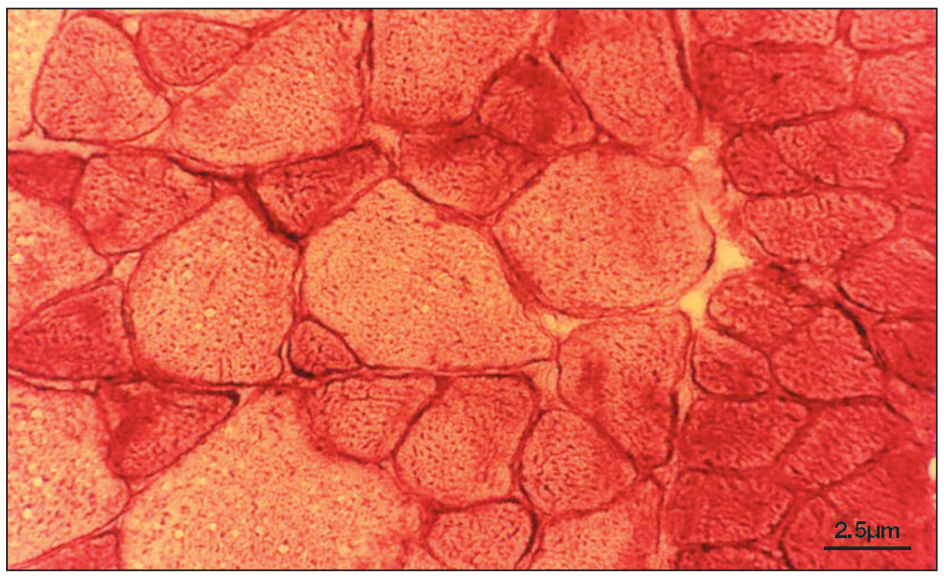

Fig. 3. Oncorhynchus mykiss. The cross-section of the superficial and intermediate muscle layers by PAS (Periodic Acid Schiff). Enzymatic differentiation of tissues (superficial layer - intermediate layer).

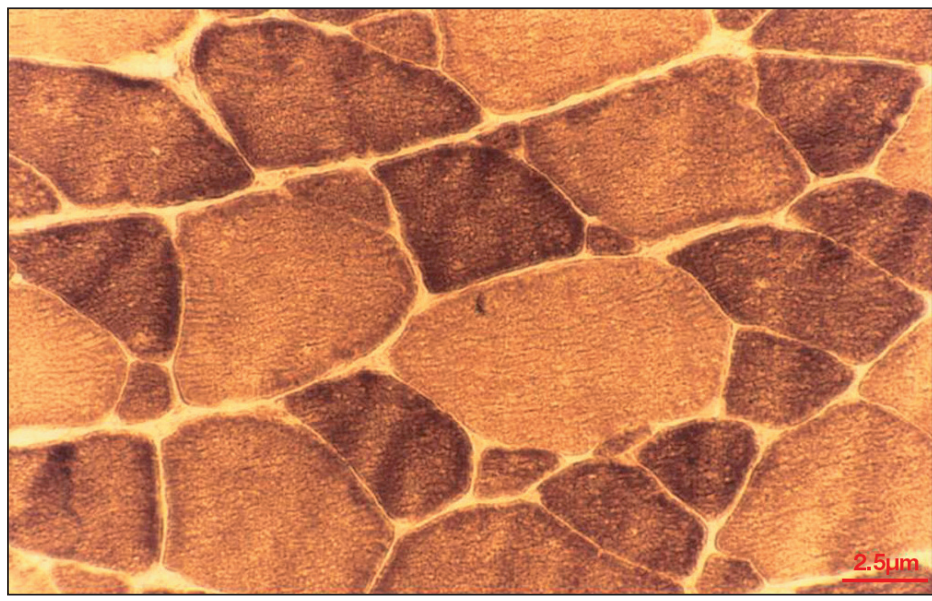

Fig. 4. Salmo trutta. Lateral section of the posterior ventral muscle by acid ATPase reaction. The red fibres are acid stable and the white fibres are alkaline stable. 
Plate IV

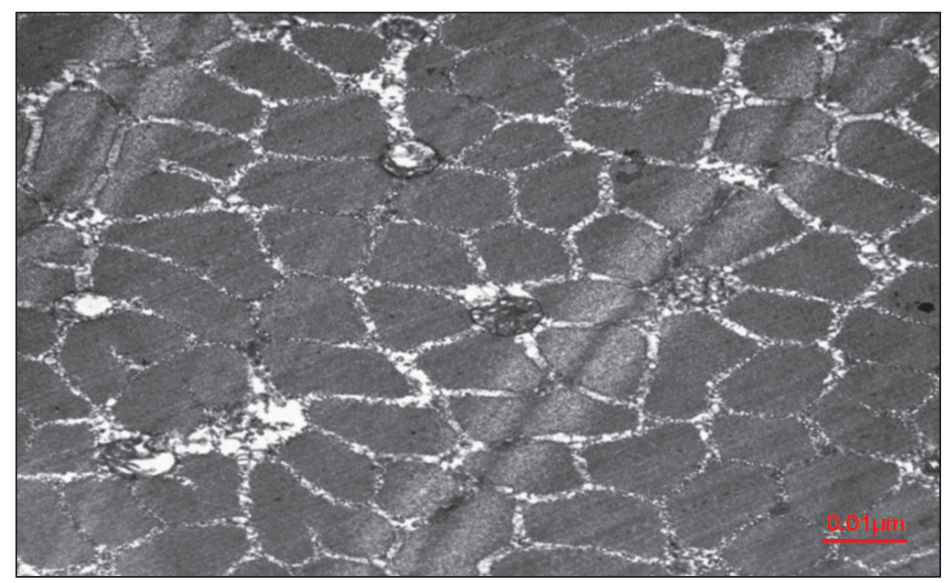

Fig. 5. Salmo trutta. Ultrastructural analysis of the cross-section of the dorsal muscle (contrast with lead citrate). 